\title{
Cyclic evolution of residual stresses on a dry race of thrust rolling bearing mapped by XRD
}

\author{
Carvalho Filho, E.T. ${ }^{1}$; Medeiros, J.S. ${ }^{1}$; Medeiros, J.T.N¹ Martinez, L. G. ${ }^{2}$ \\ 1 Group of Tribology Studies and Structural Integrity, Federal University of Rio Grande do Norte, Natal, RN, Brazil \\ 2 Nuclear and Energy Research Institute, Materials Science and Technology Center, São Paulo, SP, Brazil
}

\begin{abstract}
Nowadays, minimum lubrication is imperious in mechanical systems and its upper limit is the "dry condition". Similarly, materials, manufacturing processes, heat treatments, mounting and maintenance of these systems are constrained on high competitive cost matrix that constitutes a complex scenario of the residual stresses and material strength points-of-view. The aim of this investigation was measure the cyclic evolution of residual stresses on a race of a 51100 thrust rolling bearing manufactured of DIN $100 \mathrm{Cr} 6$ steel after tests in a tribometer under a dry condition. The $\operatorname{Sin}^{2} \psi$ XRD method was used for mapping these residual stresses. Three zones on circumferential and radial directions of the rolling race, after $10^{4}, 10^{5}$ cycles and at collapse were selected for the evaluation and compared to the new ("as received") condition. Central tendency and dispersion of the measurements are discussed and compared to published data. Keywords: Residual stresses, X-Ray Diffraction, Structural Integrity, Tribology.
\end{abstract}

\section{Introduction}

Machine elements subjected to movement of sliding and rolling under load increasingly require a reliable assessment of their stress-strain states in every moment of the life in service. Increasing speeds and contact pressures intensified by the tendency for miniaturization of the systems expands this relevance. In this context, the residual stresses complexity and importance require increasing reliability in their assessment in structures and mechanical components.

The residual stress concerns the remaining stress in a volume of material after ceasing external solicitations that may be, mechanical, magnetic, thermal, etc. [1]. These stresses can be inserted or relieved to improve some material properties such as resistance to fatigue [2]. Residual stresses have a maximum value (in magnitude), that is the yield point of the material. Coto et al [3] concluded that the machining parameters chosen are fundamental to the remaining stresses state in the final component. The "Mannesmann" process of manufacturing pipes is the most used for seamless tubes and generates an anisotropic stress state in the final product [4].

\section{Materials and Methods}

Three equidistant regions were selected on the radial and circumferential directions (Figure 1a) of a flat race thrust ball bearing 51100 for two kinds of investigation (1) the residual stresses on the race (a) new, (b) after $10^{4}$ cycles, (c) after $10^{5}$ cycles and (d) at the collapse (at $3.376 \times 10^{5}$ cycles) and (2) Vickers Micro- Hardness $\left(\mathrm{HV}_{0.025}\right), 1 \mathrm{~mm}$ between indentations performed for statistical analysis by ANOVA. The chemical composition of the race is described in Table 1 and its microstructure is shown in Figure 1 (b).

\begin{tabular}{|c|c|c|c|c|c|c|c|}
\hline C & Si & Mn & $\mathrm{Cr}$ & $\mathbf{P}$ & $\mathrm{S}$ & Mo & $\mathrm{Fe}$ \\
\hline 1.0 & 0.28 & 0.30 & 1.52 & $\leq 0.025$ & $\leq 0.025$ & $\leq 0.08$ & Ral \\
\hline
\end{tabular}

A tribometer was instrumented to run tests for rolling contact fatigue, as shown in Figures $2 \mathrm{a}$, and $2 \mathrm{~b}$. The room temperature was controlled to $24 \pm 2{ }^{\circ} \mathrm{C}$. A specimen plan was adopted as the lower bearing race, used in inverted position with the aim of having an initial contact nonconforming, thus intensifying the nominal Hertz pressure contact (3.24 GPa). The upper bearing race was used in conventional position, rotated at 1100 $\mathrm{rpm}(1.38 \mathrm{~m} / \mathrm{s})$. The rolling elements were the original of the bearing, consisting of 9 spheres (with $4.65 \mathrm{~mm}$ diameter each) separated by a steel cage. 
Materials Science and Engineering

Table 2 - Values (MPa) of the measures of residual stresses and equivalent stresses.

\begin{tabular}{ccccc}
\hline & New & $10^{4}$ Cycles & $10^{5}$ Cycles & $3.376 \times 10^{5}$ Cycles \\
\hline LI Radial & -877 & -966 & -972 & -987 \\
LI Circumferential & -725 & -733 & -832 & -765 \\
LII Radial & -702 & -819 & -826 & -862 \\
LII Circumferential & -887 & -980 & -1001 & -923 \\
LIII Radial & -852 & -952 & -1219 & -1161 \\
LIII Circumferential & -766 & -926 & -931 & -821 \\
Equivalent Stress LI & 812 & 873 & 910 & 897 \\
Equivalent Stress LII & 810 & 910 & 926 & 894 \\
Equivalent Stress LIII & 812 & 939 & 1104 & 1034 \\
\hline
\end{tabular}

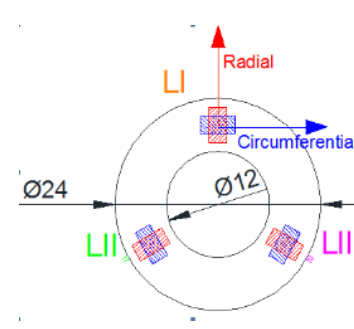

(a)

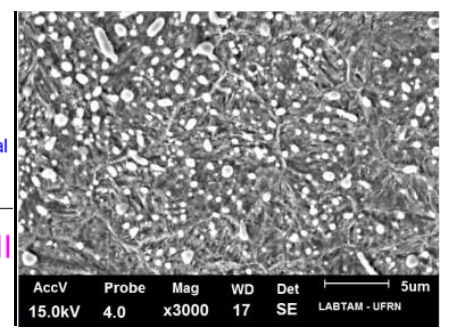

(b)

Figure 1 - a) Flat race ball bearing drawings (in $\mathrm{mm}$ ) in which are shown the regions of analysis. b) Microstructure of the 52100 steel, showing grain boundary, morphology and carbides distribution

\subsection{Analysis of residual stress by XRD}
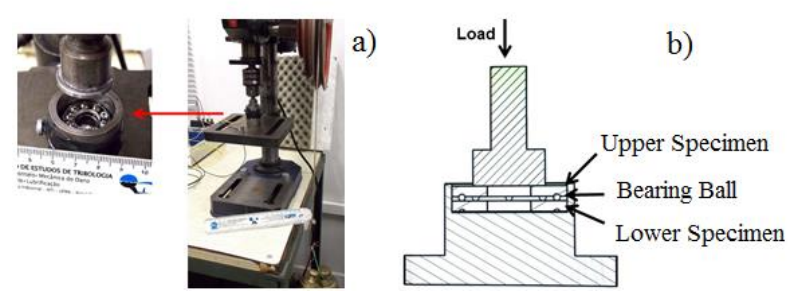

Figure 2 - Special bench instrumented for testing contact fatigue.

The principle of residual stresses measurement by X-ray diffraction is based on the distortion of the crystal lattice caused by deformations in the linear-elastic regime. In order to obtain the X-ray diffraction is necessary to comply the Bragg's Law (Noyan \& Cohen, 1987) [5]:

$$
\eta \lambda=2 d \sin \theta
$$

Where $\lambda$ is the wavelength of the radiation used, which influences the penetration of X-rays, $\theta$ is half the Bragg angle, and "d" is the interplanar spacing for a given reflection of a crystalline material and $n$ is a an integer. Assuming the $\sin ^{2} \psi$ method for the residual stresses measurements, the specimen is rotated by an angle $\psi$ (angle between the normal of the specimen surface and the diffracting planes normal). Relating with elasticity law and Poisson coefficient, we can calculate the value of the stresses according following equation.

$$
\sigma_{\mathrm{x}}=-\frac{E}{2(1+v)} \times \cot \theta_{0} \times \frac{\partial\left(2 \theta_{\psi \mathrm{x}}\right)}{\partial\left(\sin ^{2} \psi\right)} \text {. }
$$

An X-ray diffractometer Shimadzu 7000 equipped with $\mathrm{Cr}_{K \alpha}$ radiation $(2.29 \AA)$ was used for measurements. The $2 \theta$ scanning was from $150.5^{\circ}$ to $162.5^{\circ}$ at $0.05^{\circ}$ steps, $7.5 \mathrm{sec} / \mathrm{step}$ counting time and reference angle of $155.0^{\circ}$ (211 planes reflection). It was used parallel beam geometry with $2 \mathrm{~mm}$ of horizontal aperture. The $\psi$ angles analyzed were $0^{\circ}, 10^{\circ}, 20^{\circ}, 30^{\circ}$ and $40^{\circ}$. The material parameters used were: Elasticity modulus $=210 \mathrm{GPa}$ and Poisson coefficient $=0.30$.

The calculation of the equivalent stresses was made from equation (3) using the Von Mises criterion;

$$
\frac{\sqrt{2}}{2} x\left[\left(\sigma_{1}-\sigma_{2}\right)^{2}+\left(\sigma_{2}-\sigma_{3}\right)^{2}+\left(\sigma_{1}-\sigma_{3}\right)^{2}\right](3)
$$

Where $\sigma_{1}=$ stress in the radial direction, $\sigma_{2}=$ stress in the circumferential direction and $\sigma_{3}=$ stress in axial direction. $\sigma_{3}$ is considered to be 0 .

\section{Results and discussion}

It was observed cutting, ploughing and prow formation, the three distinct mechanisms of abrasive wear, as is shown in Figures 3 and 4.

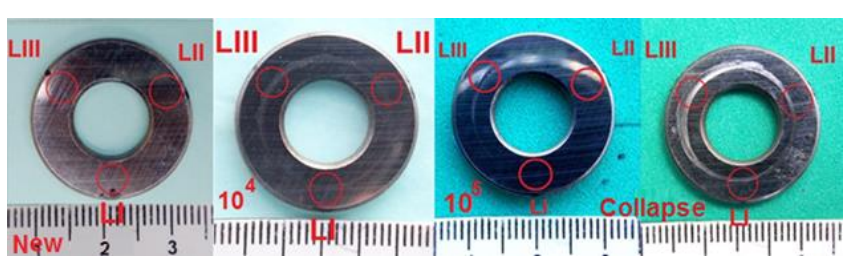

Figure $3-$ Wear evidences in bearing race at regions $2 \mathrm{~h}$ (LII), 6h (LI) and $10 \mathrm{~h}$ (LIII). 


\section{Workshop of Applied Crystallography to Materials Science and Engineering}

\section{Blucher}

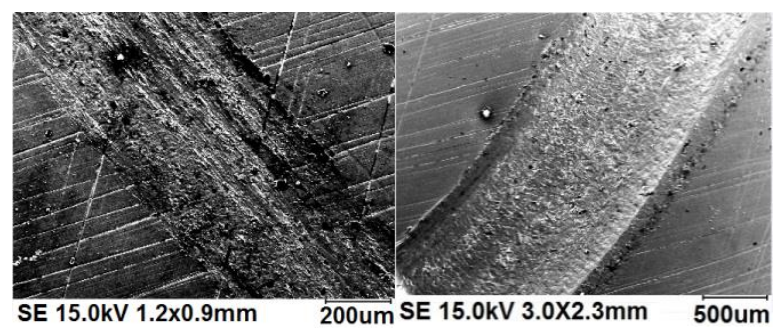

Figure $4-$ Wear evidences at bearing race after collapse at regions $2 \mathrm{~h}$ (LII) e 10h (LIII) respectively.

In Table 2 are presented the results of compressive residual stresses and also show the expected surface anisotropy in the plane of the bearing, due to the manufacturing process, in circumferential and radial directions, which propagates after three subsequent cycling.

The evolution of equivalent stresses (residual) and Micro-Hardness are shown in Figure 5.

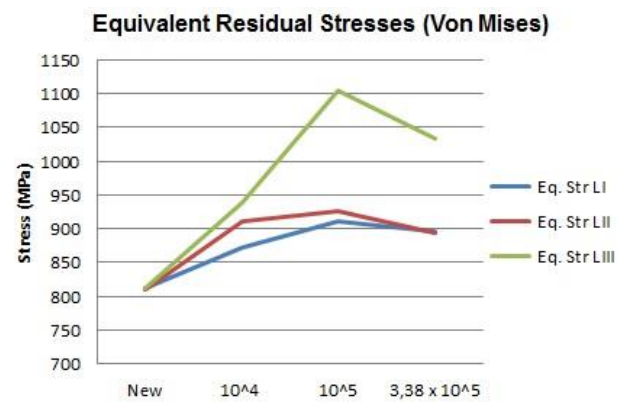

Figure $5-$ a) Evolution of equivalent stresses.

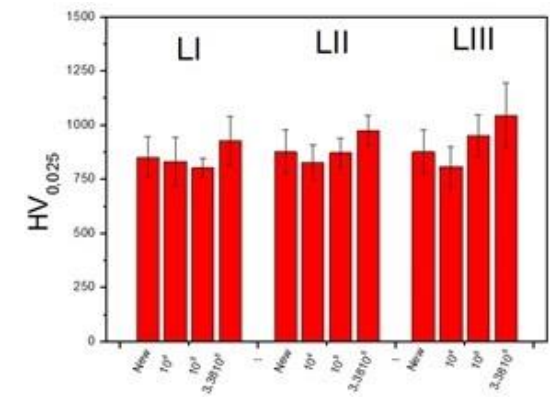

Figure 5 - b) Micro-Hardness $\mathrm{HV}_{0.025}$, with evidences of running-in.

After $10^{4}$ cycles the stresses in the regions investigated increased $15 \%$ compared to the initial value. For $10^{5}$ cycles the LIII region showed values $19 \%$ and $20 \%$ higher than the region 1 and 2 , respectively. At $3.376 \times 10^{5}$ cycles, the equivalent stress at this region was $15 \%$ higher compared to other regions. This behavior can be attributed to an inclination of the table support, evidenced by the nonuniform wear in the regions, observed in the region LIII and shown in Figure 3. The micro-hardness results presented in Figure 5.b were analyzed by ANOVA for a level of $95 \%$ confidence, with the aid of software Statigraphics ${ }^{\circledR}$. The results showed statistically significant differences in the region LIII. It can be observed the running-in at the region $\mathrm{LI}$ up to $10^{5}$ cycles, while at the regions LII and LIII can be observed a trend in increase on hardness for the same lifetime. The micro-hardness results show a possible phase transformation in the microstructure (formation of white layer) at the region LIII [6].

\section{Conclusions}

For all measurements the values of residual stresses were compressive. For some regions were found differences between the directions and regions analyzed, due to the manufacturing process and part of the form deviations of the components studied.

Micro-hardness measurements allowed to identifying the end of the running-in of the three regions analyzed, identifying longer lifetime for the region of less wear on bearing race. Measurements of residual stress and the behavior of their rates suggest that $10^{5}$ cycles where possibly the level at which the stress reaches the yield point of the material, despite the different conditions associated with the form deviations of the system and balancing the tribometer used.

\section{Acknowledgements}

Carvalho Filho, E.T., express the gratitude for the availability of the structure of the Center for primary processing and reuse of produced water and residue (NUPPRAR-UFRN) and the Laboratory Refining and Environmental Technologies (LABTAM-UFRN).

\section{References}

[1] LU, J. Handbook of Measurement of Residual stresses, vol. 1. SEM, Bethel 1996.

[2] CHOI, Y. A study on the effects of machining-induced residual stress on rolling contact fatigue International Journal of Fatigue 31, p. 1517-1523, 2009.

[3] COTO, B. et al.; Influences of turning parameters in surface residual stresses in AISI 4340 steel, Int. J. Adv. Manuf. Technol. p. 911-919, 2011

[4] TELLES, P.C.S., Tubulações industriais: materiais, projeto e desenho - Rio de Janeiro: LTC Livros Técnicos e Científicos Editora S.A., Reimpressão 2008, 10ª Edição, 2001.

[5] NOYAN, I.C.; COHEN J.B., Residual Stress, SpringerVerlag: New York, 1987.

[6] JOUINI, N.; et al.; The ability of precision hard turning to increase rolling contact fatigue life, Tribology International $\mathrm{p}$. 141-146, 2013. 